\title{
LARGE 718 FORGINGS FOR LAND BASED TURBINES
}

\author{
R.C. Schwant*, S.V. 'l hamboo*, A.F. Anderson*, \\ C.B. Adasczik**, B.J. Bond**, L.A. Jackman**, J.F. Uginet*** \\ * GE Power Systems, Schenectady, New York, USA \\ **Allvac, an Alleghany Teledyne Company, Monroe, North Carolina, USA \\ *** FORTECH-Division Airforge, Pamiers Cedex, France
}

\begin{abstract}
The largest 718 ingots ever produced have been forged into $2000 \mathrm{~mm}$ ( 79 inch) diameter disks for land based turbines. The $686 \mathrm{~mm}(27 \mathrm{inch})$ diameter ingots are made by a triple melt process and weigh as much as $9000 \mathrm{~kg}$ (20,000 pounds). VAR melting parameters were varied in a development program to establish the processing window. Freedom from harmful positive (freckle) segregation has been verified by destructive evaluation of several full size ingots. Fine grain sizes of ASTM 9 to 11 have been achieved in the forgings through a multi-step billet and closed die forging practice. This fine grain size permits detection of small indications via ultrasonic testing, in all areas of each forging. Testing of material obtained through destructive evaluation of full size disks has shown mechanical properties to be within the same range as is found in smaller aircraft engine disks.
\end{abstract}

\section{$\underline{\text { Introduction }}$}

Since the development of the first gas turbine, the drive for lower cost electrical power has lead to more efficient land based power systems. Increased efficiency has been achieved through higher firing temperatures and expanded turbine size. The high operating temperatures and the large size of the components used in modern turbines have, however, created new, more difficult demands on the materials and processes employed to make these power plants. Turbine wheels have provided a particularly difficult challenge because the class of materials (steel) used to make the turbines of the 1980's, was already stressed to the limits of its temperature and strength capability.

Use of superalloys developed for the jet engine industry provides a model for dealing with the challenges posed by still higher efficiency land based turbines, without resorting to increased component cooling that imposes parasitic capability losses. However, jet engine technology does not yield direct solutions to the problems which face land based turbine designers,

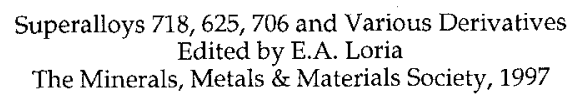


because the sizes of the components in the two systems are significantly different and create different cooling rate effects during heat treatment. The main issue is the aging of the $\gamma^{\prime}$ phase (FCC, $\mathrm{Ni}_{3}[\mathrm{Al}, \mathrm{Ti}]$ ) used to strengthen most jet engine alloys. The $\gamma^{\prime}$ precipitates form and grow very rapidly, but not so rapidly as to be a processing problem for the relatively small disks used in aircraft. However, disks made from $\gamma^{\prime}$ alloys in sizes large enough for land based turbines, would overage during cooling from heat treatment, losing much of their strength.

Superalloys which harden through the formation of $\gamma^{\prime \prime}\left(\mathrm{BCT}, \mathrm{Ni}_{3} \mathrm{Nb}\right)$ are more suitable for components with large cross sections because over-aging may be avoided due to the slower growth kinetics of this phase. The first use of an alloy of this type in a large scale rotating part, was the introduction of alloy $706^{(1)}$ in GE's F class turbines in 1989. Use of 706 permitted firing temperatures to jump from a maximum of $1093 \mathrm{C}(2000 \mathrm{~F})$ to more than $1288 \mathrm{C}(2350$ F). However, recent efforts to design new advanced gas turbines, with firing temperatures in excess of $1427 \mathrm{C}(2600 \mathrm{~F})$ (see Figure 1), has required another upgrade for the wheel material.

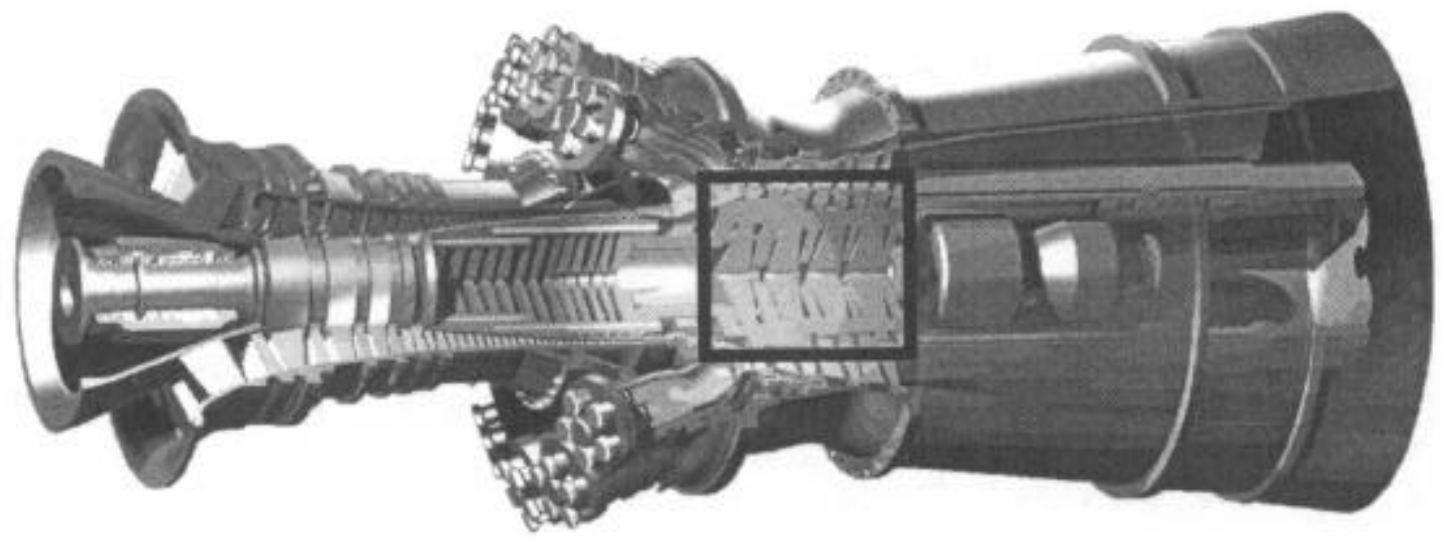

Figure 1 - Advanced Gas Turbine with Seven Alloy 718 Turbine Disks

Alloy 718 was a natural candidate for the upgrade, having been well characterized over many years of use. However, component size was again an issue. The largest 718 ingots made previously for rotating components were about $3800 \mathrm{~kg}$ and the advanced gas turbine requires ingots of about $9000 \mathrm{~kg}$. Ingot size, until now, has been limited by a fear of harmful "freckle" segregation. A further difficulty arises from the desire to maintain low forging temperatures to achieve a fine grain size in the final product. The high flow stress of 718 at low temperatures challenges the capabilities of the largest forge presses in the world. So it was with this as a background, that Allvac, Fortech and GE launched a two and a half year program to melt and forge the largest ever 718 rotating components.

\section{Melting Technology Development}

A triple melting process consisting of VIM (Vacuum Induction Melting) followed by ESR (Electroslag Remelting) and then VAR (Vacuum Arc Remelting) was selected from the onset of this program. Use of VAR as the final melt step provides the best opportunity to minimize segregation. ESR reduces inclusions and facilitates a more consistent VAR operation by providing a sound electrode for VAR. VIM is used to cast the raw alloy starting stock into an ESR electrode. This triple melted approach had been successfully applied to Alloy 706 in diameters as large as $914 \mathrm{~mm}^{(2)}$ and to Alloy 718 in diameters up to $610 \mathrm{~mm}$, but this turbine disk application required a significantly larger 718 ingot. 
Casting of superalloys becomes more difficult as ingot size increases. Heat extraction during melting becomes more difficult with increasing ingot diameter, hence local solidification times can become longer and molten pools can become deeper. This can increase the tendency towards macrosegregation such as freckles and microsegregation such as banding. Larger ingots and electrodes can also generate higher thermal stresses during heating and cooling. A VAR diameter of $686 \mathrm{~mm}$ was chosen for this program because it represents the smallest diameter capable of generating the required $9000 \mathrm{~kg}$ forge mult at a forgable length.

Prior to any melting, computer modeling of the VAR process was conducted to evaluate the feasibility of successfully extending the diameter of Alloy 718 triple melted ingots from $610 \mathrm{~mm}$ to $686 \mathrm{~mm}$. A model developed at Sandia National Laboratory under SMPC (Specialty Metals Processing Consortium) was used. VAR modeling is not yet sufficiently developed to accurately predict segregation such as freckles and white spots, but useful comparisons can be made. Modeling results indicated it would be possible to produce $686 \mathrm{~mm}$ triple melt Alloy 718 ingots without segregation problems. For example, results in Table I indicate that an increase in VAR ingot diameter from $610 \mathrm{~mm}$ to $686 \mathrm{~mm}$ leads to relatively small increases in local solidification time and dendrite arm spacing at the ingot axis. Note that the simulations for Table I used the same current voltage and melt rates for all ingot diameters.

Table I - VAR Simulation Results* for Various Ingot Sizes

(Current, voltage and melt rate are the same for all diameters)

\begin{tabular}{l|ccc}
\hline VAR Ingot Diameter, $\mathrm{mm}$ & 508 & 610 & 686 \\
\hline & & & \\
Electrode Diameter, mm & 457 & 508 & 635 \\
Control Volume Height, mm & 762 & 914 & 1029 \\
Liquidus Depth, mm & 165 & 153 & 140 \\
Solidus Depth, mm & 291 & 277 & 269 \\
Local Solidification Time at $\Lambda$ xis, sec & 3057 & 5368 & 5746 \\
Dendrite Arm Spacing at Axis, $\mu \mathrm{m}$ & 116 & 140 & 143 \\
\hline
\end{tabular}

*Results generated using SMPC code BAR4.3

The chemistry for standard premium quality Alloy 718 was altered slightly for $686 \mathrm{~mm}$ diameter ingots. Niobium was slightly reduced because it has a strong segregation tendency during solidification. ${ }^{(3)}$ Carbon was lowered to minimize carbides and freckles formation. The lower carbon also increases the amount of niobium available for strengthening as $\gamma^{\prime \prime}$ because less niobium will be tied up as carbides. ${ }^{(4,5)}$ Also, silicon was lowered to minimize the stability of Laves phase. ${ }^{(1)}$ Table II provides a typical analysis.

$$
\begin{aligned}
& \text { Table II - Typical Composition, Weight \% } \\
& \begin{array}{llllllllll}
\underline{\mathrm{C}} & \underline{\mathrm{Cr}} & \underline{\mathrm{Mo}} & \underline{\mathrm{Nb}} & \underline{\mathrm{Ti}} & \underline{\mathrm{Al}} & \underline{\mathrm{Si}} & \underline{\mathrm{Fe}} & \underline{\mathrm{B}} & \underline{\mathrm{Ni}} \\
0.01 & 17.9 & 3.02 & 5.03 & 0.9 & 0.44 & 0.025 & 18.2 & 0.003 & \text { Balance }
\end{array}
\end{aligned}
$$

Three full scale trial ingots, referred to as T1, T2, and T3, were made to establish a practice for producing $686 \mathrm{~mm}$ diameter triple melted Alloy 718 . The basic processing route was the same on all ingots: VIM, ESR, VAR, homogenize and press forge from $686 \mathrm{~mm}$ diameter to $356 \mathrm{~mm}$ diameter. The final melt operation of VAR is the most critical melting step with regard to 
metallurgical quality. Therefore, considerable effort was devoted to optimizing steady state melt parameters and developing robust practices for electrode thermal processing, VAR start up and hot topping.

It is known that high melt rates lead to a deep melt pool and promote the formation of harmful freckle segregation, while melting too slowly results in a shallow melt pool and creates conditions where solidification white spots can form. Hence, each trial ingot was produced with several different melt rates to determine the acceptable processing window. Each melt rate continued for several estimated melt pool depths to establish steady state solidification conditions before being changed to the next melt rate. The positions of each melt rate transition zone and each region with a uniform melt rate were tracked throughout processing. Several intentional power interruptions with durations of up to 90 seconds were also evaluated.

\section{Ingot Evaluations}

Melt Pool - Each ingot was forged to a billet to aid evaluation of segregation and ultrasonic inspection. However, the top of one ingot was removed in the as-cast condition to view the VAR pool profile. This profile was marked by magnetic stirring for 20 minutes during steady state melting followed by an immediate power shut off. Figure 2 is a longitudinal section from that ingot top which shows a pool depth of approximately $145 \mathrm{~mm}$. This is in good agreement with the model predication of $140 \mathrm{~mm}$ for the liquidus temperature.

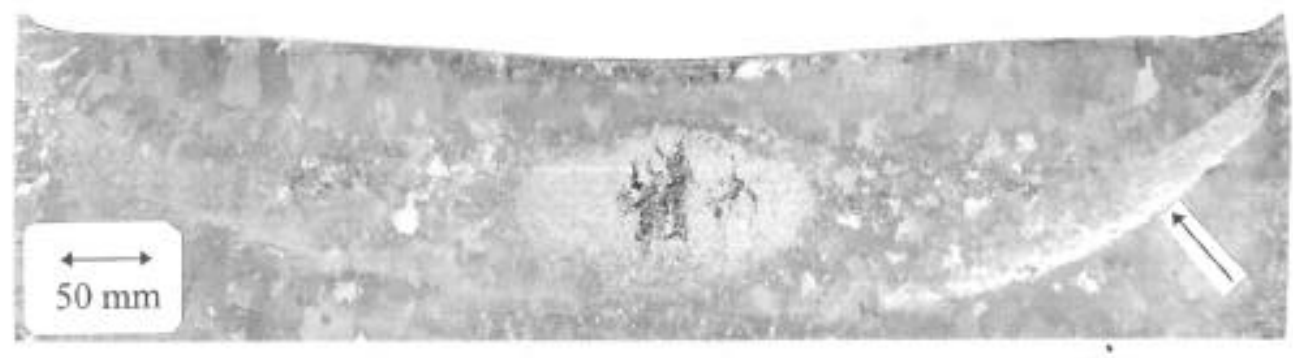

Figure 2. Pool Profile for $686 \mathrm{~mm}$ Diameter Ingot Melted at the Optimum Rate

Billet Macrostructure - The macrostructure of each billet was evaluated by examination of macro etch plates and ultrasonic inspection. The etch plates were taken at several locations within each melt rate and each plate encompassed the full cross section of the billet. As shown in Figure 3, freckle segregation was found in some of the high melt rate areas. All freckles contained numerous carbides. Laves phase was also present in some of the freckles. It was identified with scanning electron microscopy using energy dispersive X-ray spectroscopy (EDS)

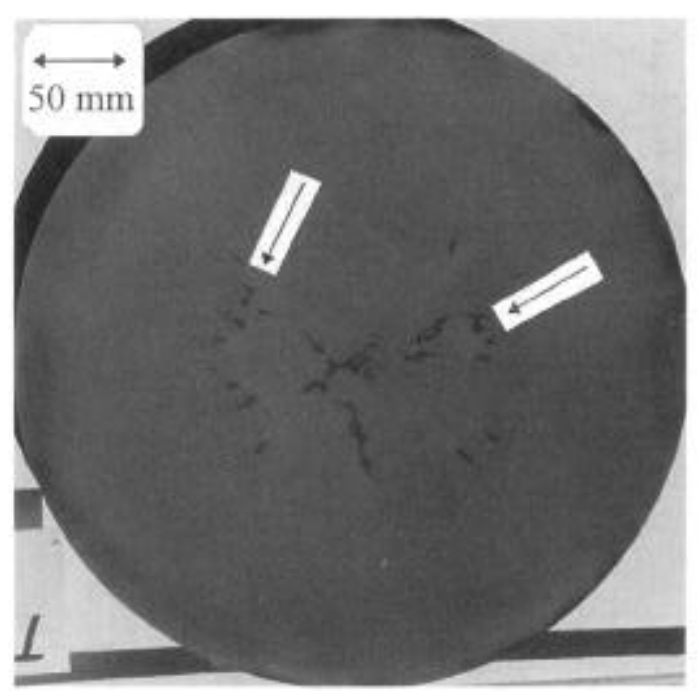

Figure 3. Freckles at Melt Rate 17\% Above Optimum 
The sonic testing, which was performed to a $1.2 \mathrm{~mm}$ flat bottomed hole size, detected several indications in high melt rate areas. These locations were removed as part of the etch plate evaluations. All of the indications were at mid-radius to center locations and were associated with cracked freckle segregation. Table III relates ultrasonic indications and freckles to melt rate for each ingot. Consistency between ingots was excellent. Ultrasonic indications and freckles occurred only at melt rates exceeding the optimum melt rate by $11 \%$ or greater. The safe melt rate range is well within equipment control capabilities.

Table III - Influence of VAR Melt Rate on Defects

\begin{tabular}{|c|c|c|c|}
\hline Ingot & Melt Rate* & $\begin{array}{c}\text { Ultrasonic } \\
\text { Indications }\end{array}$ & Freckles \\
\hline T1 & $-17 \%$ & no & no \\
T1 & $-6 \%$ & no & no \\
T1 & $+6 \%$ & no & no \\
& & & \\
\hline T2 & $-6 \%$ & no & no \\
T2 & $+6 \%$ & no & no \\
T2 & $+17 \%$ & yes & yes \\
& & & \\
\hline T3 & at optimum & no & no \\
T3 & $+6 \%$ & no & no \\
T3 & $+11 \%$ & yes & yes \\
T3 & $+17 \%$ & yes & yes \\
\hline
\end{tabular}

${ }^{*}$ Melt rates are presented as a percentage difference from the optimum rate

As expected, the lowest melt rate showed a high frequency of solidification white spots. Figure 4 shows a low melt rate slice with numerous solidification white spots associated with a ring pattern near the outer diameter. A micro of a prominent white spot is included as Figure 5. It has a "half moon" shape which is typical of many solidification white spots. SEM-EDS was done on a total of sixteen white spots taken from the three heats of the program. None of the white spots were associated with excessive carbides, carbonitrides or other inclusions. Chemistry differences between the matrix and the white spots (Figure 6) are minor and typical of solidification white spots. These solidification white spots were all located near the billet surface.

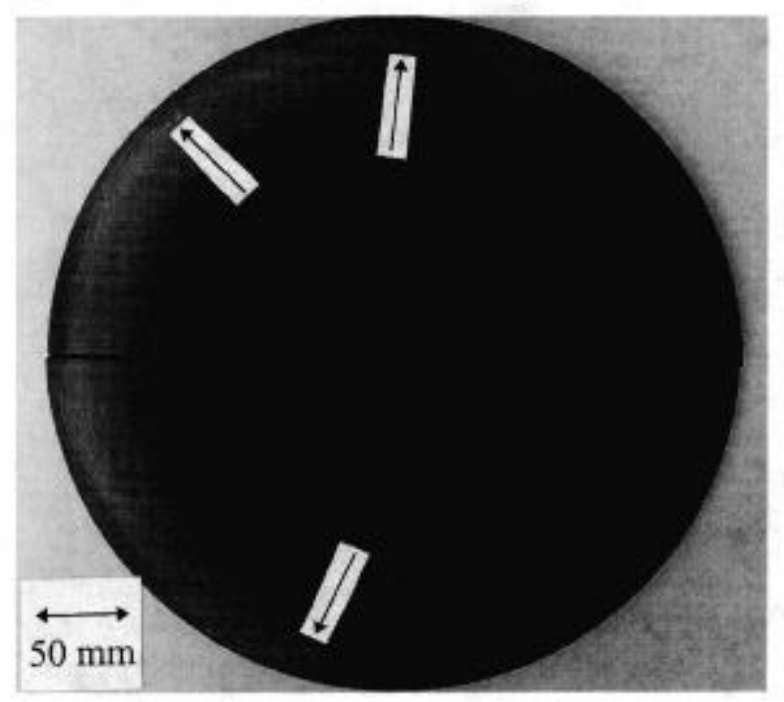

Figure 4. Solidification White Spots Following Ring Pattern at Melt Rate 17\% Below Optimum 


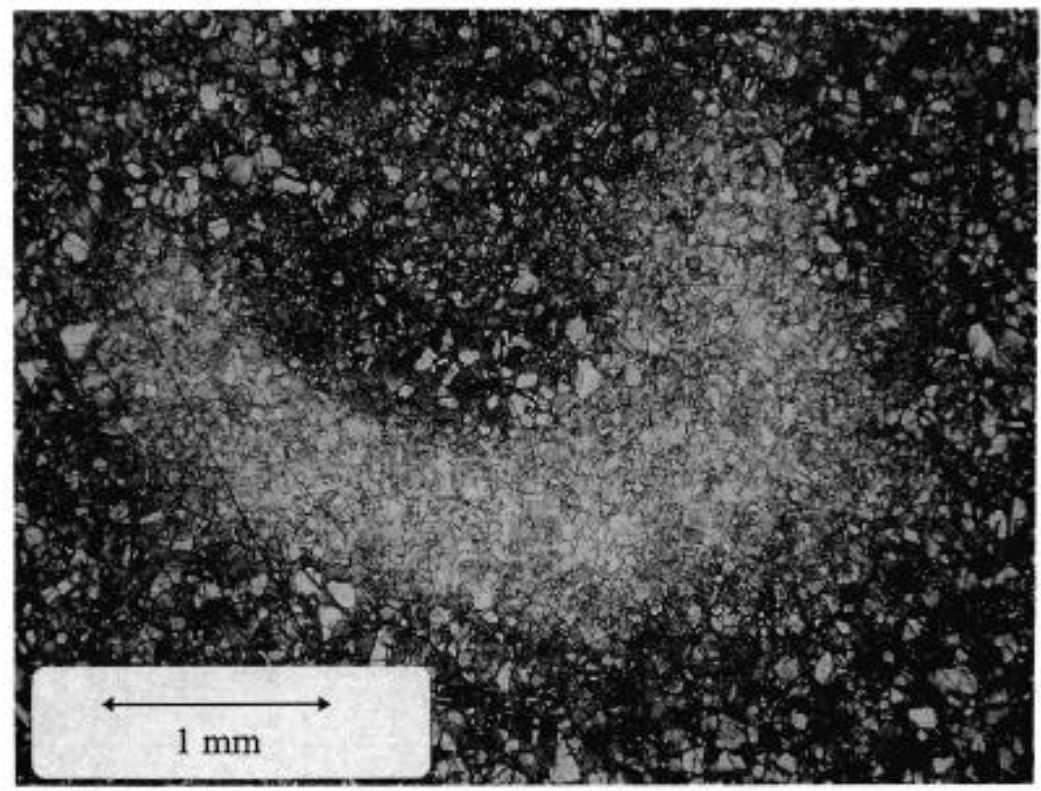

Figure 5. Solidification White Spot

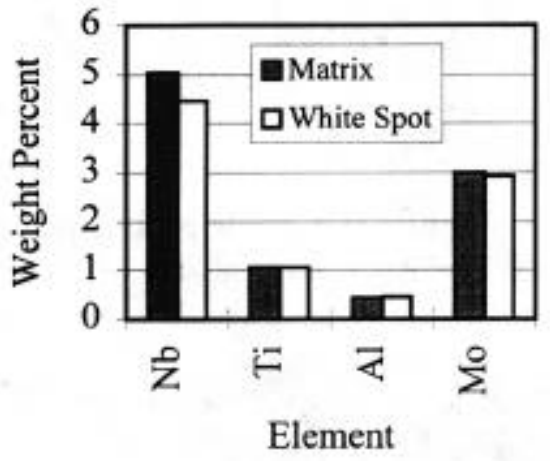

Figure 6. Average Chemistry Difference Between Solidification White Spots and Matrix
Table IV - Banding Evaluation at Billet Center and Surface, Melt Rates $-6 \%,+6 \%$ and $+17 \%$ of Optimum

Carbide evaluation - Micro samples from each heat were examined in the longitudinal direction for carbide size and distribution. They were found to be comparable to carbide structures in billets made from $580 \mathrm{~mm}$ and $610 \mathrm{~mm}$ Alloy 718 ingots. A "worst field" is shown in Figure 7 for a center location.

Microsegregation - To assess the tendency towards banding from chemical segregation, a series of samples from various melt rates of heat $\mathrm{T} 2$ were upset forged and heat treated. The cubes were $50 \mathrm{~mm} \times 50 \mathrm{~mm} \times 64 \mathrm{~mm}$, with the $64 \mathrm{~mm}$ in the longitudinal direction of the billet. Both billet center and edge material was tested. After press forging from $64 \mathrm{~mm}$ high to 16 $\mathrm{mm}$ high, micro specimens were cut from the center of the forged sample and heat treated to the parameters listed in Table IV to precipitate and then solution delta phase. None of the samples showed any grain growth at $995^{\circ} \mathrm{C}$, and all coarsened uniformly after exposure to 
$1030^{\circ} \mathrm{C}$. This indicates excellent homogeneity from center to surface at all melt rates tested, and is equivalent to results from billets made from $508 \mathrm{~mm}$ and $610 \mathrm{~mm}$ diameter triple melt ingots. The homogenization practice for the $686 \mathrm{~mm}$ diameter ingot is similar to that for smaller ingots but has been modified slightly.

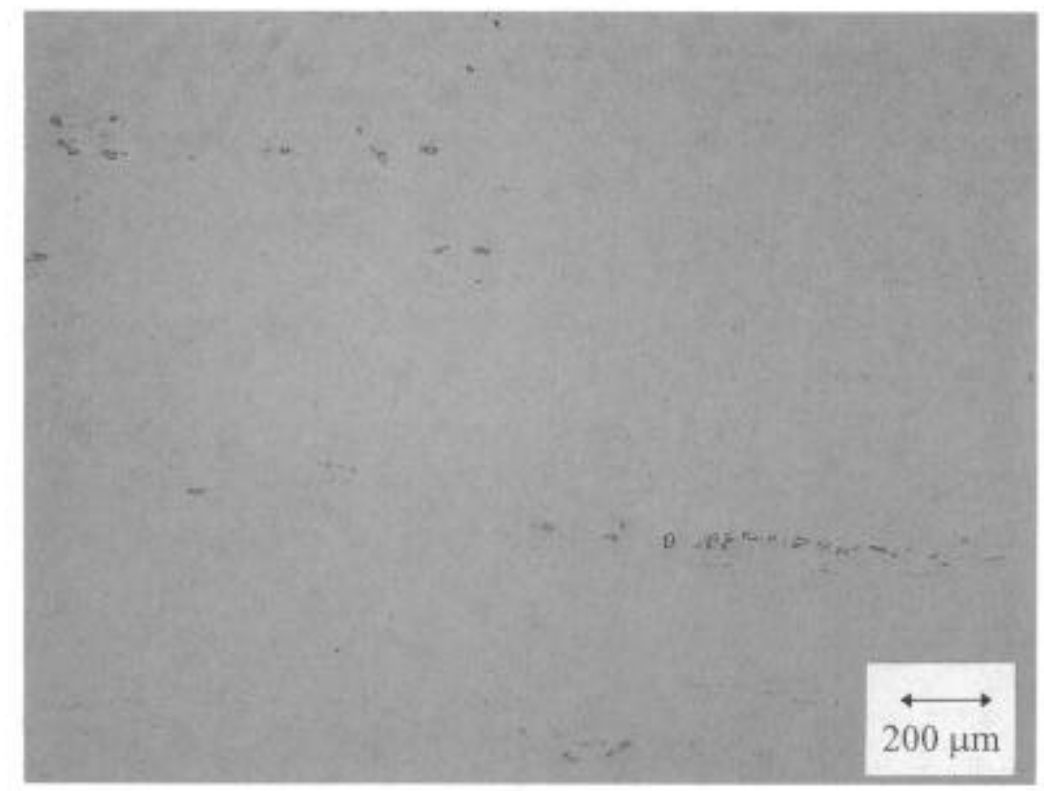

Figure 7. Billet Center Longitudinal Carbide Structure - Worst Field of View

\section{Forging}

The forging process was divided into two parts. The first part consisted of forging above the delta solvus to create a billet with a grain size of ASTM 2 to 4 . The second part of the process involved forging below the delta solvus to achieve a final grain size finer than ASTM 8.

\section{Billet Forging}

It is generally recognized that direct upsetting of an ingot does not break up the large as-cast grains in the low strained areas along the top, bottom and axis of an ingot. In order to refine the grain size in all areas it is necessary to work the ingot in different directions via an upset and draw practice. The cogging sequence for such a large ingot is critical. The forging temperature, the amount of strain per forging pass and the time required to forge must all be balanced so as to promote recrystallization while at the same time avoiding surface cracking. A single upset and draw can not provide the high strains at low temperatures needed to achieve a fine grain structure without cracking the ingot surface, so a cascade of three different upset and draw sequences at decreasing temperatures was chosen.

It was necessary to make ingots with very high length to diameter $(\mathrm{L} / \mathrm{D})$ ratios to meet the required input weight for the disks. This lead to use of container dies during the initial upsetting, to prevent buckling. It was necessary to design container dies with a particular geometry and volume adapted to each ingot weight. The first sequence of upsetting was performed in three different container dies under a 65,000 metric ton press. A sharp increase in 
the forging pressure at the end of each upset was used to insure that the container dies were completely filled, a necessity before moving to the next container.

Further billet forging was performed under a smaller press which was better suited to manipulating the billet during the draw operations. This imposed a further constraint to keep the diameter in a range acceptable for the capacity of the press at each temperature. Special care was required in the choice of upset ratios, lubrication, insulation and die temperature. $\mathrm{Re}$ heating times were also carefully controlled to avoid grain growth and to manage the thermal gradient from surface to center, taking in account the large dimensions of the product at its various stages. The potential for surface cracking, which increases with decreasing forging temperature, was controlled through close regulation of the forging sequence, depth of each forging pass, temperature and time to forge. A successful process was achieved as evidenced by minimal surface conditioning losses and a fully recrystallized microstructure at both ends of the billet.

The first billet forging trial included an intermediate second homogenizing treatment as part of the billet practice. However, after comparison with an a direct forging sequence without an intermediate homogenization, the benefit was not obvious, and it was decided to use the direct sequence for production. Figure 8 shows the final microstructure at the centerline of the billet.

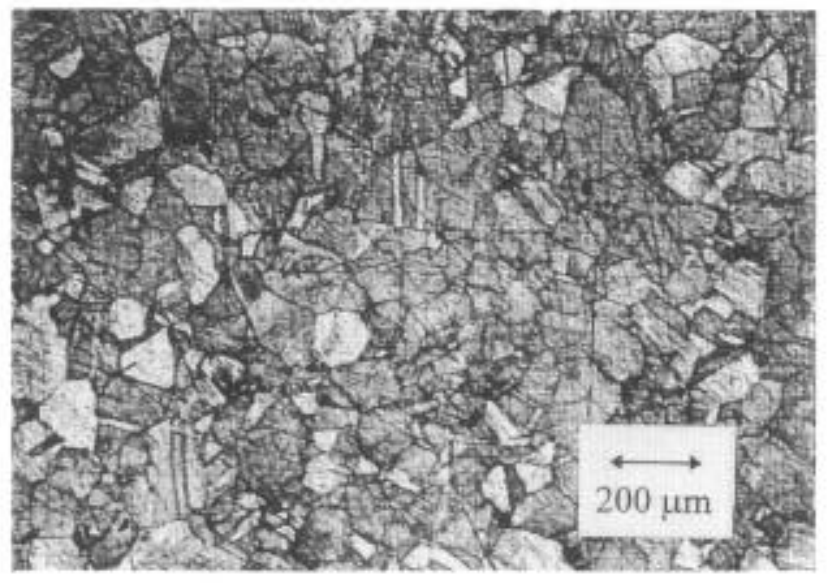

Figure 8. Billet Microstructure

\section{Final Forging Sequence}

Prior to production, a series of lab scale experiments were performed to determine the best approach to processing the full scale part. Following this, a $3 / 8$ scale trial forging was produced. The material for this work came from the $356 \mathrm{~mm}$ billet used to evaluate the melting parameters used for the first $686 \mathrm{~mm}$ diameter trial ingot. The final cogging temperature for the billet was in the range 1900 to $1950 \mathrm{~F}$ and yielded a starting grain size for this study in the range ASTM 4-7.

The lab studies entailed isothermal compression of both $25 \mathrm{~mm}$ cylindrical specimens and wedge specimens. The specimen geometry for the wedge (truncated cone) specimen is given in reference 7 . The wedge specimens provide a variation in strain over a single sample and therefore the effect of strain on microstructure can be evaluated with one specimen. The lab studies showed that dynamic recrystallization occurs both above and below the delta solvus. However, a single upset was not able to provide 100 percent recrystallization. Some coarse deformed grains remained even at high strains $(0.8$ to 1.0$)$. These coarse grains did not recrystallize even after solution treatment below the solvus. A two step upset was, however, able to produce a $100 \%$ recrystallized structure. When both upsets were done below the solvus the recrystallized grains were very fine (ASTM 8-10). This worked for a range of strain values from 0.2 to 1.0 . 
The sub-size trial forging was produced with a multiple upset process based on the results from the lab studies. Sections were heat treated to aid determination of the optimum solutioning temperature. Cooling from the solutioning temperature was controlled to simulate a full size forging. A temperature at the upper end of the sub solvus range was chosen to maintain a fine microstructure and achieve the needed tensile properties. Figure 9 and Table $\mathrm{V}$ show that a fine uniform microstructure and good properties were achieved from the bore to the rim with this temperature.

Table V

Mechanical Properties of a Sub-size Trial Forging

\begin{tabular}{|c|c|c|c|c|}
\hline Location & $\begin{array}{c}.2 \% \mathrm{YS} \\
(\mathrm{MPa})\end{array}$ & $\begin{array}{c}\text { UTS } \\
(\mathrm{MPa})\end{array}$ & $\begin{array}{c}\text { \% Elong. } \\
\text { Borpy Energy } \\
\text { (Joules) }\end{array}$ \\
\hline Bore Tangential & 1082 & 1361 & 21.6 & $24-25$ \\
\hline Rim Tangential & 1073 & 1392 & 23.8 & $23-25$ \\
\hline
\end{tabular}

Full scale disks were forged on the 65,000 metric ton press using multiple upsets below the delta solvus. Forging below the solvus helped avoid grain growth at the surface of the billet during the long preheating time necessary to achieve the forging temperature. The initial upset forging employed the same container dies used for the billetizing. This was followed by upsetting between sets of dies in the shape of the part. Again particular attention was given to the thermal parameters to meet the aimed microstructure in the whole volume of the part. Retention of heat during transfer from the furnace and while in contact with the dies was considered to be of primary importance. A ceramic spray was used to minimize the surface temperature losses during the handling. All of the preheating times were calculated based on the characteristics of this protective coating and the calculated cooling during the closed die forging. Figure 10 shows the final as forged shapes of two of the disks.

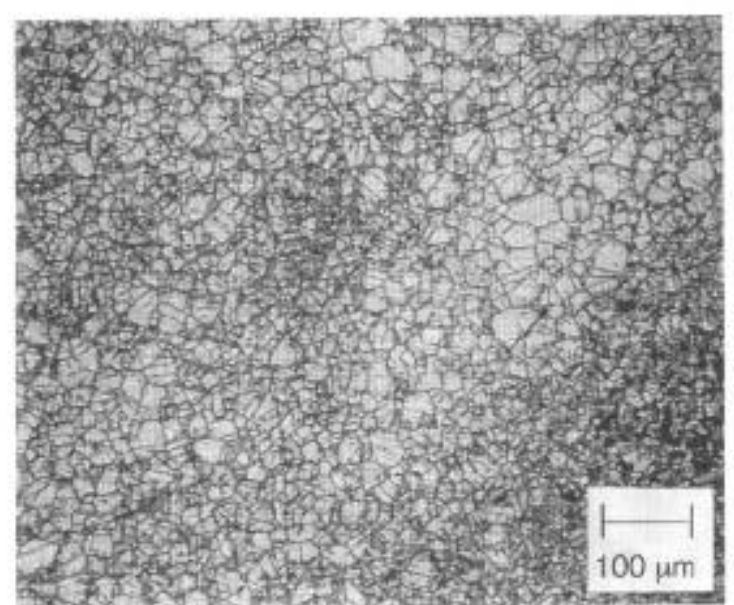

Figure 9a. Sub-size Microstructure at Bore

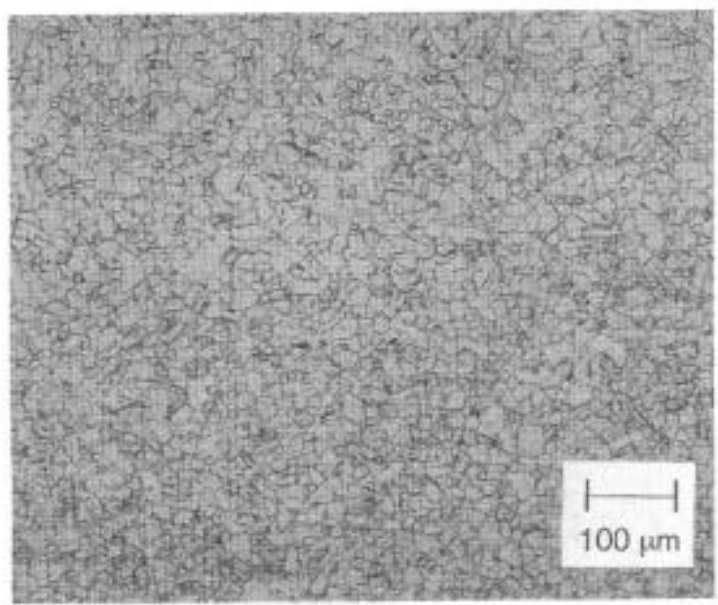

Figure 9b. Sub-size Microstructure at Rim

\section{First Part Results}

The first full size forging was ultrasonic inspected, by both Fortech and GE, and then cut up for evaluation. Ultrasonic examination included the following tests: 
Radial $2.25 \mathrm{MHz}$ from rim

Axial $2.25 \mathrm{MHz}$ on all axial faces

$2.25 \mathrm{MHz}$ in pitch/catch mode from the axial faces

Background noise in these fine grained forgings permitted detection of indications smaller than $0.8 \mathrm{~mm}$ equivalent flat bottom hole diameter. No indications were found.

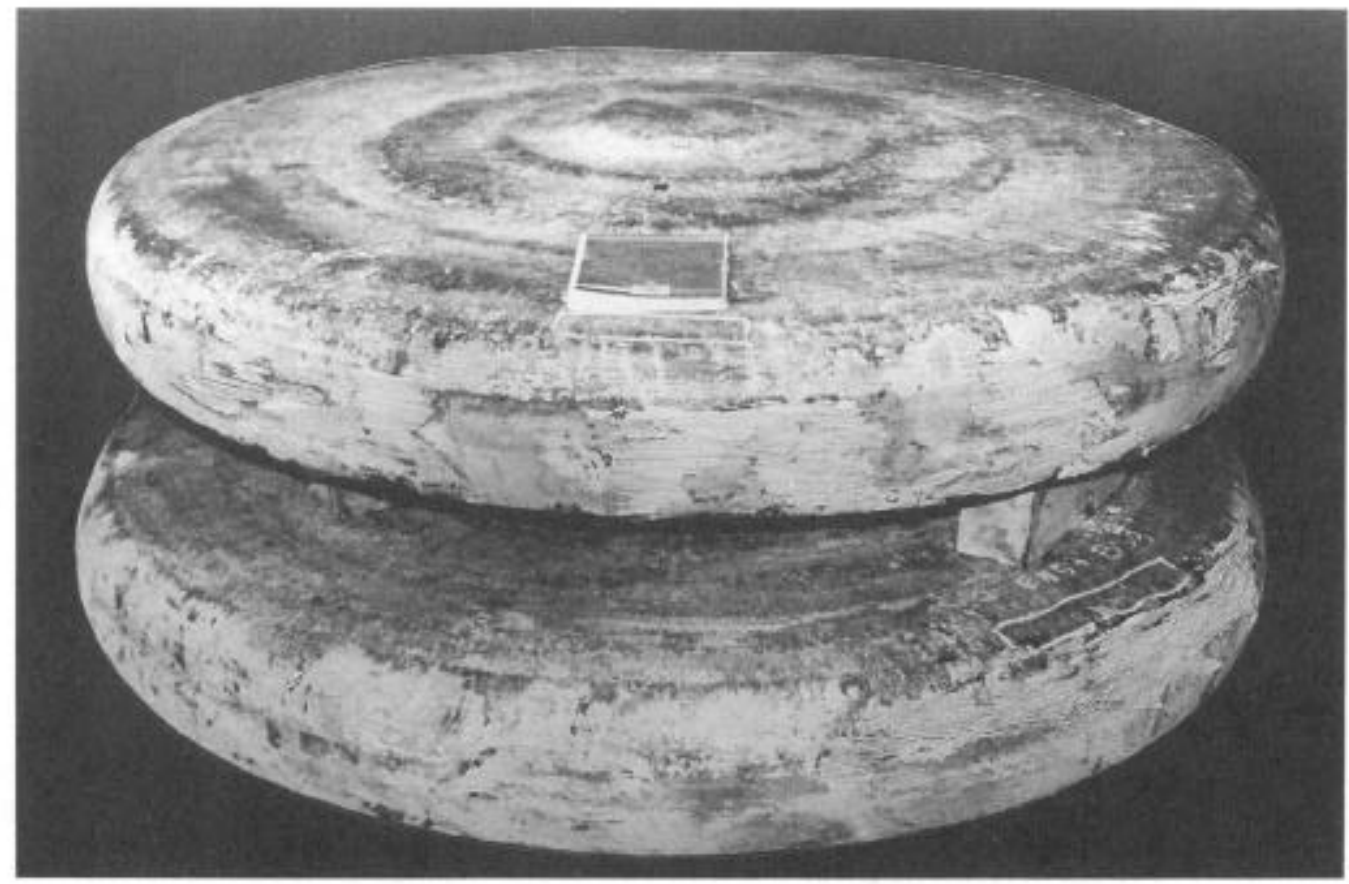

Figure 10. Full Size (2000 mm Diameter) Alloy 718 Disks

\section{Mechanical Properties}

The wheel was cut into sections for evaluation of the internal structure and mechanical properties. The microstructure was similar to the that of the sub-size forging with a typical grain size of ASTM 9 to 11. Figure 11 shows ultimate tensile strength and yield strength values as a function of location and temperature. The ultimate strength values are comparable to values in smaller disk forgings. The yield strength values are somewhat lower than those found in smaller forgings because of the combination of slower cooling rate from the solution temperature and the lower level of niobium.

Low cycle fatigue results from several locations in the wheel forging are shown in Figure 12. These values are as good as or better than fatigue properties measured in smaller disks. Fatigue crack growth rates were found to be similar to that of smaller disks as seen in Figure 13.

\section{$\underline{\text { Conclusion }}$}

The difficulties in producing high quality disk forgings up to $2000 \mathrm{~mm}$ in diameter have been overcome. Freckle-free $686 \mathrm{~mm}$ diameter ingots weighing up to $9000 \mathrm{~kg}$ are attainable. Careful forging of these ingots can be made to yield contoured disks with a typical grain size of 
ASTM 10. These disks have excellent ultrasonic penetrability and properties similar to smaller disk forgings.

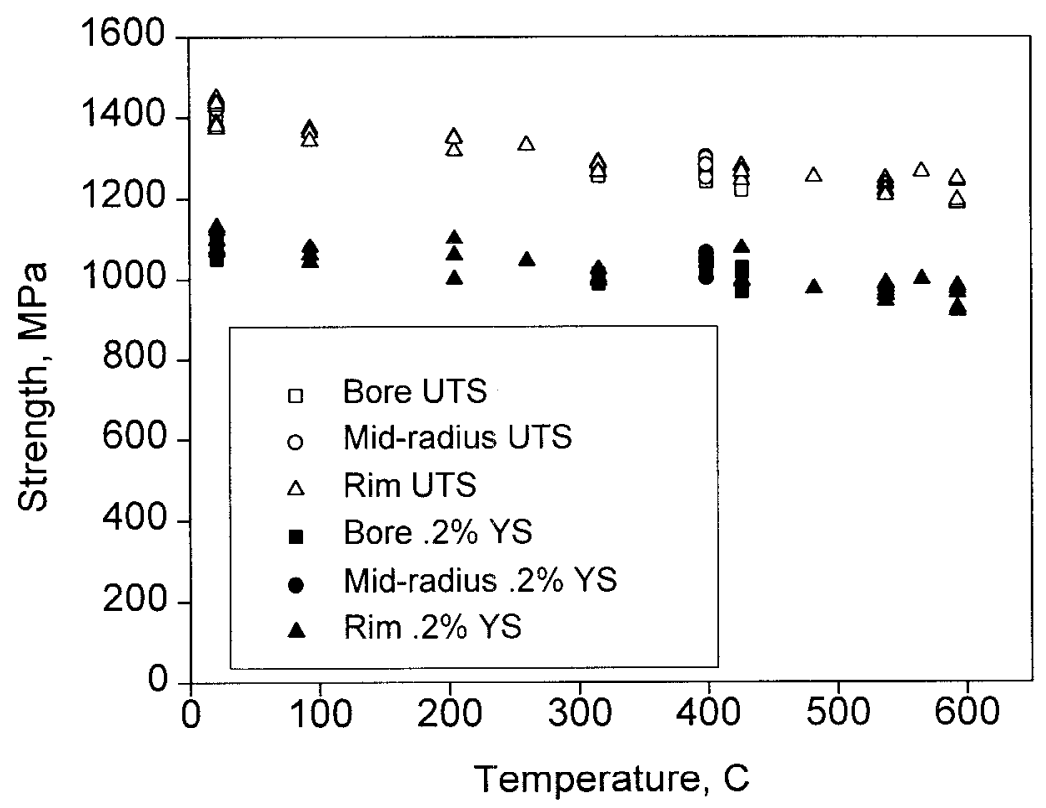

Figure 11.Variation in Tensile and Yield Strength with Temperature

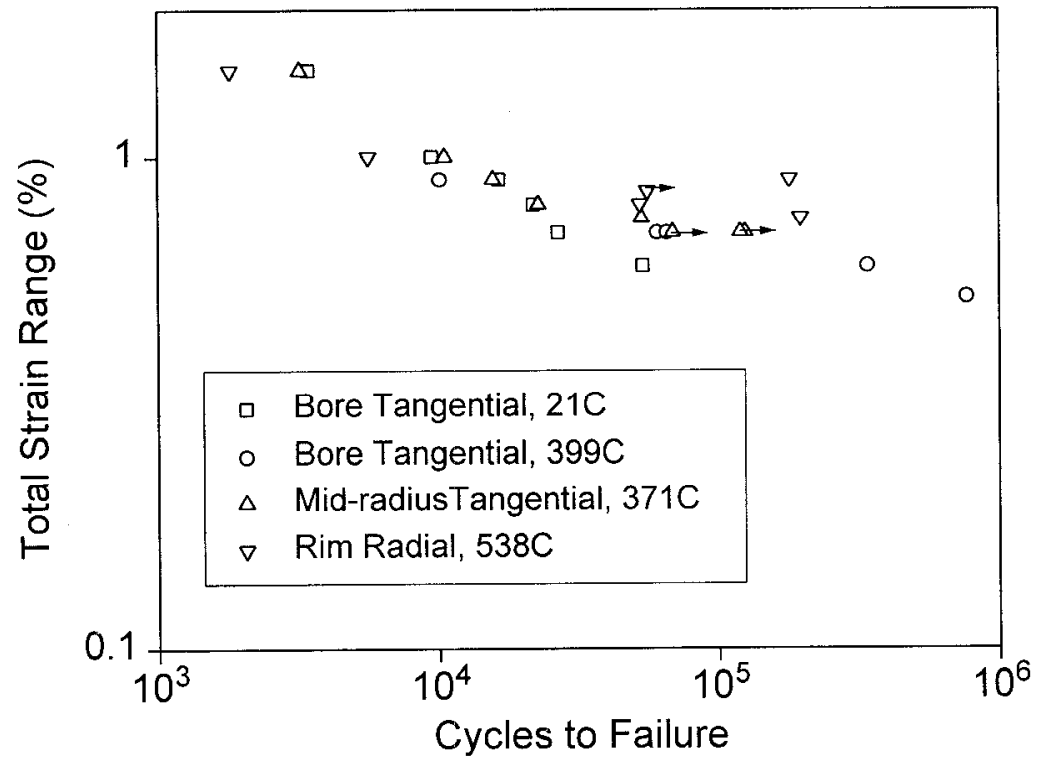

Figure 12. Low Cycle Fatigue, $R=0,20 \mathrm{cpm}$ 


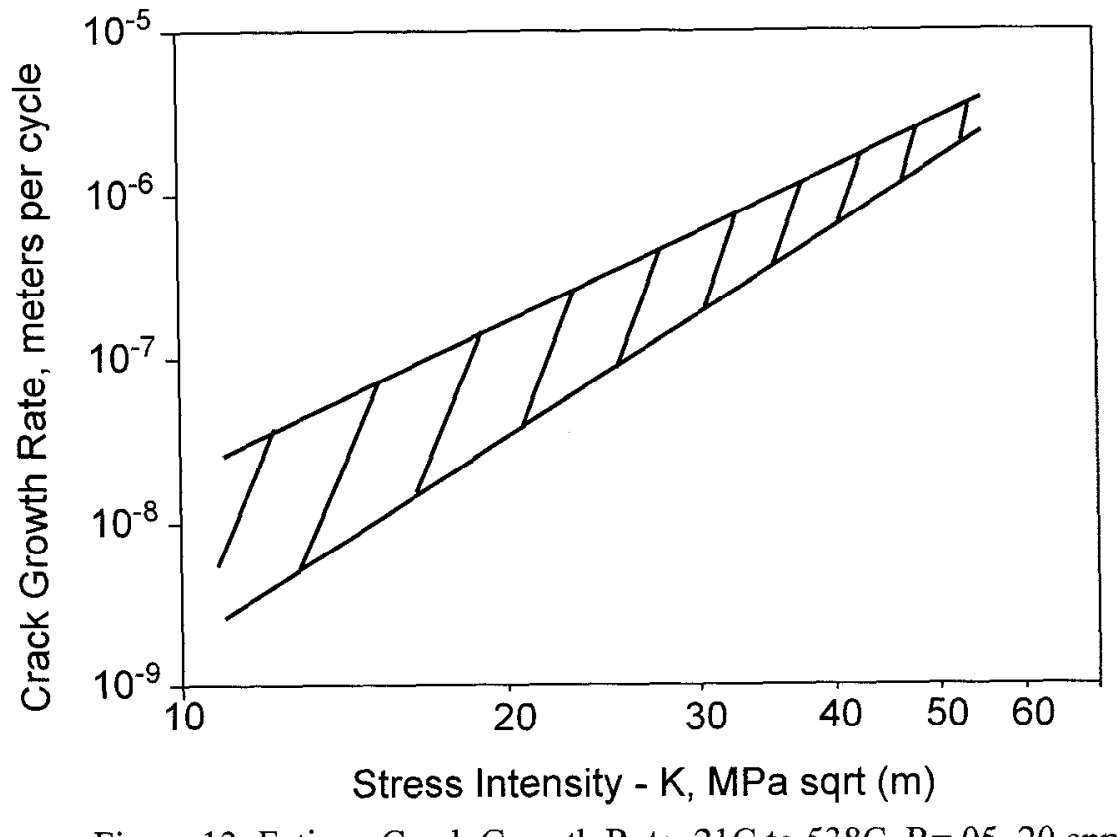

Figure 13. Fatigue Crack Growth Rate, $21 \mathrm{C}$ to $538 \mathrm{C}, \mathrm{R}=.05,20 \mathrm{cpm}$

Acknowledgments

The authors would like to acknowledge Ramesh Minisandram, Carlos Ruiz, John Silvestri and Jefr Russell for their contributions to this effort..

References

1. P. Schilke, J. Pepe and R. Schwant, "Alloy 706 Metallurgy and Turbine Wheel Application," Superalloys 718,625, 706 and Various Derivatives, ed. E. A. Loria, TMS, 1994, 1-12.

2. A. Helms, C. Adasczik and L. Jackman, "Extending the Size Limits of Cast/Wrought Superalloy Ingots," Superalloys 1996, R. Kissinger et al., eds., TMS, 1996, 427-433.

3. M. Cieslak et al., "The Solidification Metallurgy of Alloy 718 and Other Nb-Containing Superalloys," Superalloy 718 Metallurgy and Applications, ed. E. A. Loria, TMS, 1989, 59-68.

4. C. Ruiz et al., "Creep Behavior of Fine Grain, Low Carbon Allvac 718," Superalloys 718 , 625, 706 and Various Derivatives, ed. E. A. Loria, TMS, 1994, 523-534.

5. J. Moyer, "Extra Low Carbon Alloy 718," Superalloys 1984, M. Gell et al., eds., TMS, $1984,443-454$.

6. L. Jackman, G. Maurer and S. Widge, "White Spots in Superalloys," Superalloys 718, 625. 706 and Various Derivatives, ed. E. A. Loria, TMS, 1994, 153-166.

7. S. Thamboo, "Thermomechanical Behavior and Microstructure Development of Alloy 706", Superalloys 718, 625, 706 and Derivatives ed. E. A. Loria, TMS, 1996. 